WellBeing International

WBI Studies Repository

1993

\title{
Animal Welfare and Individual Characteristics: A Conversation Against Speciesism
}

\author{
Marc Bekoff \\ University of Colorado \\ Lori Gruen \\ University of Colorado
}

Follow this and additional works at: https://www.wellbeingintlstudiesrepository.org/acwp_awap

Part of the Animal Studies Commons, Cognition and Perception Commons, and the Other Anthropology Commons

\section{Recommended Citation}

Bekoff, M., \& Gruen, L. (1993). Animal welfare and individual characteristics: A conversation against speciesism. Ethics \& behavior, 3(2), 163-175.

This material is brought to you for free and open access by WellBeing International. It has been accepted for inclusion by an authorized administrator of the WBI Studies Repository. For more information, please contact wbisr-info@wellbeingintl.org.

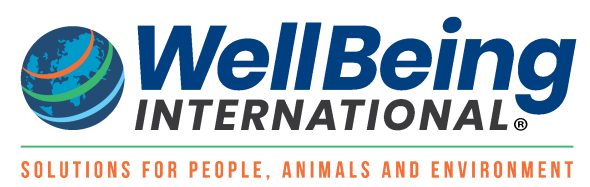




\title{
Animal Welfare and Individual Characteristics: A Conversation Against Speciesism
}

\author{
Marc Bekoff and Lori Gruen \\ University of Colorado
}

\section{$\underline{\text { KEYWORDS }}$}

speciesism, animal welfare, cognition, pain, suffering, moral community

\begin{abstract}
It seems impossible for a human being not to have some point of view concerning nonhuman animal (hereafter animal) welfare. Many people make decisions about how humans are permitted to treat animals using speciesist criteria, basing their decisions on an individual's species membership rather than on that animal's individual characteristics. Although speciesism provides a convenient way for making difficult decisions about who should be used in different types of research, we argue that such decisions should rely on an analysis of individual characteristics and should not be based merely on species membership. We do not argue that the concept of species is never useful or important. To make our points, we present a conversation among a skeptic, an agnostic, and a proponent of the view that our moral obligations to an animal must be based on an analysis of that individual's characteristics. In the course of the discussion, concepts such as personhood, consciousness, cognitive ability, harm, and pain are presented, because one's understanding of these concepts informs his or her ethical decisions about the use of animals by humans.
\end{abstract}

It would be impossible for anyone but a severely detached human being not to have some point of view concerning animal welfare. Many people make decisions about how humans (moral agents) are permitted to treat animals (moral patients) using speciesist criteria (Ryder, 1975/1983, 1989) that lead to prejudicial judgments based on species membership and not on individual characteristics (see also Bekoff, 1992; DeBlieu, 1991; and Norton, 1986, for discussions of how this view might inform decisions about the preservation of species). Although we do not argue that the concept of species is never useful or important, the ambiguity of the term species (Geist, 1992; Gittleman \& Pimm, 1991), and the presence of great intraspecific variation (Gibbons, 1991; Lott, 1991; McGrew, 1992; Swartz \& Evans, 1991), precludes its use as a basis for moral deliberation. Although speciesism provides a convenient way (or excuse) for 
making difficult decisions about who should be used in different types of research (e.g., trying to decide whether to do research on a normal chimpanzee or on a severely brain-damaged human infant, the latter of whom it is presumed is highly likely to die soon after birth based on past experience with such individuals), we argue here that such decisions should rely on an analysis of individual characteristics.

James Rachels (1990), using Darwinian evolutionary biology and claims about evolutionary continuity to frame and to ground his argument, has recently written extensively on this topic. He develops an ethic that he calls moral individualism, an ethic that should not be confused with one that grants elevated status to an individual and his or her preferences and interests, but rather which suggests that "how an individual may be treated is to be determined, not by considering his own particular group memberships, but by considering his own particular characteristics" (Rachels, 1990, p. 173). The rules of moral individualism are species-neutral and run counter to the notion of speciesism. Rachels (1990, p. 220) noted, "if it is wrong to use humans in experiments, then it is also wrong to use animals, unless there are relevant differences between them that justify a difference in treatment." Of course, a dilemma arises in which the similarities between humans and nonhumans have to be emphasized to justify the application of an animal model, whereas the differences have to be highlighted in order to justify the research ethically. But, "one cannot have it both ways" (Rachels, 1990, p. 220).

In addition, the very process of determining what constitutes a similarity and what constitutes a difference will largely depend on the reason such a determination is being sought and what the desired outcome is. For example, consider a black domestic cat, a black dog, and a black panther. Which two are the most similar? To answer this question, we must first answer another, namely, why do we want to know? If we are concerned with similarity because we are interested in knowing which of these animals would make the best companion, we would most likely conclude that the cat and the dog are more similar to one another in this context than either is to the panther. If we are concerned with similarity because we want to know about taxonomic affinity, obviously the cat and the panther are more similar to one another than either is to the $\operatorname{dog}$ (N. A. Davis, personal communication, February, 1992).

Our view, like Rachels's, emphasizes the need to focus on individual characteristics. However, our position is more comprehensive in that we take a broader comparative perspective and appeal more to common sense and compassion. By appealing to an ethic that focuses on individual characteristics rather than on membership in a specific species or group, we also allow for an emphasis on cultural considerations in context (Croft, 1991; Gaard \& Gruen, in press; Noske, 1989; Pluhar, 1988; Routley \& Routley, 1979; Wenzel, 1991). This awareness is important, particularly when discussing human relations regarding animals, because it allows us to avoid criticisms of cultural imperialism. This type of ethic would permit one to ask, "Is it ethically correct or proper for the West to impose its own special view of animals on cultures whose attitudes and perceptions have evolved along very different ecological and historical lines?" (Serpell, 1991, p. 374; see also Bedau, 1991).

To illustrate our position we present a conversation among a skeptic, a proponent, and an agnostic of the view that our moral obligations to an animal must be based on an analysis of that individual's characteristics. In the course of the discussion, concepts such as personhood, consciousness, cognitive ability, harm, and pain are presented, because one's understanding of these concepts informs his or her ethical decisions about the use of animals by humans beings. In the following trialogue (a) the skeptic (SK) is willing to let a lack of knowledge or uncertainty about an individual's characteristics be used against that individual and other members of the same species; (b) the proponent (PRO) argues that we often do know more about particular characteristics than we give ourselves credit for, but is also willing to let a lack of knowledge work in favor of individual animals; and (c) the agnostic (AG), when uncertain, nonetheless can have a point of view about how to make ethical decisions regarding our treatment of individual animals. 


\section{A TRIALOGUE ABOUT COMMON SENSE, COGNITIVE ETHOLOGY, EVOLUTIONARY BIOLOGY, AND INDIVIDUAL WELFARE}

PRO: Why and how can anyone deny moral consideration to any animal? Why shouldn't all animals be respected, have their individual liberties protected, and be protected from harm?

AG: Well, perhaps it would be difficult to morally consider all animals, especially those who seem to be so distant from humans, behaviorally as well as anatomically and physiologically. I mean, who can really identify with or imagine what it would be like to be a seahorse, an aardvark, a cow, a rat, a mouse, or a bat? I think, but I really do not know, that it is easier to imagine what it would be like to be a chimpanzee or a gorilla or even a dog or a cat, because the former are more closely related to us evolutionarily and the latter are common companion animals.

SK: Look, we do not really know what it would be like to be a seahorse, an aardvark, a dog, a cat, or even a gorilla or a chimpanzee, and we really cannot know this anyway. Because we do not and cannot know what it would be like, it must mean either that there is nothing that it is like to be one of these animals or whatever it is like to be one of these animals is quite different from what it is like to be a human being. Thus, we really have few, if any, moral obligations to these animals.

AG: I do not agree. When we do not know or cannot know what it is like to be another animal, we admit that this lack of knowledge restricts us to making no further assumptions about their lives and we should at the very least leave them alone. Even if we do not consider certain individuals within our sphere of moral concern, we still should not mistreat them or use them for our own pleasures or ends.

PRO: I agree partially with AG and not at all with SK. I go one step further than AG. I claim that whether or not we do know something about other animals' lives, we recognize their moral worth and protect them as if there is something that it is like to be that animal even though it is not necessarily like what it is to be a human or person. In fact, maybe there are some animals who could be called persons and who deserve moral consideration because they have certain characteristics that fulfill the criteria that we establish for membership in the community of persons. Furthermore, maybe some individuals who are members of species other than Homo sapiens could also be called beings-dog beings, cat beings, robin beings, or chimpanzee beings. Why is the word being only used to refer to humans? Is this a not so veiled form of speciesism?

SK: Wait a minute, why do you say "a human or a person"? Are they really different? Aren't all humans persons? And, how can you even suggest that an animal could be a person? This whole line of reasoning is absurd-imagine my calling my dog a person! People would laugh at me and think that I was in need of therapy.

AG: I am not sure that I agree with you, SK. Just what criteria are necessary to justify calling any animal, human or nonhuman, a person? Is a baby a person? Is a pre-linguistic human a person? Is a mentally handicapped human a person? Is a severely brain-damaged infant a person? What about an ape who can be taught to read or use a computer? What about a human that is immobile and blind and deaf? What common characteristics can be applied to the notion of personhood that include all humans and exclude all animals? I recall that Mary Anne Warren, in a different context, suggested that the following traits are the most central to the concept of personhood: (a) consciousness, and in particular the capacity to feel pain; (b) reasoning; (c) selfmotivated activity; (d) the capacity to communicate; and (e) the presence of self-concepts and self-awareness. As Warren (1986) noted, however, "there are apt to be a great many problems 
involved in formulating precise definitions of these criteria, let alone in developing universally valid behavioral criteria for when they apply" (p. 286). ${ }^{1}$

PRO: Indeed, I think that coming up with such criteria would be difficult. Why not accept the fact that the word person is an evaluative term and that in some instances not all humans can be called persons, and if there existed such an animal that fulfilled the criteria that we establish, then that animal could be called a person? This certainly is compatible with ideas about evolutionary continuity that we use to explain the evolution of phenotypes other than behavioral ones, including the brain, so why not use the same line of thinking when considering the notion of personhood? We do not need any special evolutionary mechanisms for explaining the evolution of cognitive skills or mental states or their underlying physiological or anatomical bases.

SK: $\quad$ Once again, we really do not know if all members of a species would be able to do something just because one member of that species does it, and even if an animal could, it might still not be doing that activity in the same way that a human would do it. And certainly, findings in cognitive ethology that inform us about the likelihood of animals having rich intentional lives and also their abilities to experience pain and to suffer are often equivocal, and ideas about evolutionary continuity are not facts. I do not see why I should grant anything special to an animal, like calling a "talking" gorilla a person or considering her within the sphere of moral concern, when I just do not know if she really is comparable to a human.

PRO: I agree with your stressing the importance of individual characteristics. But how can you know or claim that all humans do things alike or that they will develop the skills that you think are necessary for moral consideration? The existence of human variability makes assertions about consistency across all humans extremely tenuous. Being able to do something that resembles what is usually taken to be a human skill is enough to entitle a being to serious consideration as to whether that individual is a person. If we are not sure we should call the individual a person and consider him or her within the sphere of moral concern, we should leave him or her alone until there is a reason to retract the label person. Furthermore, by concentrating on individual characteristics it is possible that some humans would not be persons whereas some animals could be persons. Many biologists would have no problem with this suggestion.

AG: Why not leave the animal alone and not harm him even if he is not a person, especially when we are uncertain about how to classify the individual even if we are able to develop the necessary criteria for personhood?

PRO: This might work, but there are some who would say that being a member of the moral community confers certain benefits, and if an individual was not a member of the community then it would be permissible to use him or her, but not others who were members of the community, for harmful research, or to place him or her in a zoo. We should consider all animals as members of the community and then look for individual exceptions, because it is almost always wrong for humans intentionally to cause harm to any humans or animals or purposely to kill any humans or animals who we may assume "want to go on living," including seahorses, aardvarks, bees, worms, rats, mice, birds, cats, dogs, chickens, cows, and primates.

SK: What do you mean "want to go on living"? Do animals really "want to go on living"?

PRO: I know that the phrase "want to go on living" is difficult to deal with. (For further discussion see Johnson, 1983, and Hursthouse, 1987, pp. 163ff.) What I mean is that we have no reason to believe that an individual is actively attempting or has attempted to harm herself or to take her 
own life. I confess that in the case of animals it is impossible to know whether or not an animal that does something that we consider harmful is really trying to harm herself or to take her own life. I claim that we can only assume that animals rarely, if ever, engage in self-destructive behavior, excluding, of course, animals that have been subjected to extreme social deprivation or sensory deprivation. And we cannot assume that these animals are really trying to harm or to kill themselves. To be consistent with the assertion that follows concerning how we approach animals when we are ignorant of just what it is that they can feel or can do, I maintain that our lack of knowledge about animals' intentions when they engage in abnormal self-destructive behavior, combined with what I believe to be a reasonable assertion that animals rarely, if ever, engage in self-destructive behavior for the purposes of harming or killing themselves, commits us to err on the side of the animals. I maintain that animals do not want to be caused harm.

SK: What do you mean by "caused harm"?

PRO: All right, I admit that this can be problematic, but I use it to refer to situations in which physical injury or mental damage may be produced as a result of human activity that is not related to the normal maintenance of captive animals, or to treatment that interferes with the normal activity of free-living individuals. Causing harm may take many forms, ranging from physical or mental exhaustion, restricting freedom of movement, surgery, exposure to inescapable shock, not treating illness, testing cosmetics, giving drugs, starving, force feeding, sensory and social isolation, trapping, marking individuals, and placing an animal in a situation where she cannot escape from an aggressive individual or predator. It may not always be the case that an individual responds overtly to these or other treatments. Animals, like humans, may be harmed behaviorally, anatomically, or physiologically and not show overt responses until considerable damage has been done. ${ }^{2}$ It is essential that all people who work with animals know these animals well so that they are able to assess if any harm has been done even though it is not overtly obvious. There is no substitute for careful ethological research that involves the observation and description of what are considered to be "normal" or typical individuals.

SK: Oh, come on now. How can we ever really know if harm has been done if there is no overt or measurable response?

PRO: When in doubt about the negative effects of intentional human action directed toward animals, whether for purposes of research, education, amusement, or food, we should err on the side of animals. $^{3}$ Similar suggestions have also been offered for humans. For example, with respect to pain in infants, Maria Fitzgerald (1987) claimed that the question "Do infants feel pain?" is unanswerable and unhelpful when taken at face value. She noted that it is "better to assume that they do, take a step sideways and ask the question 'Can we measure pain responses in infants and are these measures sensitive to analgesics?' " (p. 345). It may also be misleading to assume that anesthesia always causes loss of consciousness. In humans, Kulli and Koch (1991) reported that anesthesia does not always produce loss of consciousness as evidenced by patient reports after surgery.

SK: But you are asking for at least some of us to use ignorance as a guide. This seems somewhat arrogant and maybe even irrational.

PRO: No, I do not think so. By claiming that we should err on the side of individual animals when unsure about pain and suffering, I am not claiming that a failure to disprove the conclusion that an individual experiences pain constitutes proof that the being does experience pain. Rather, I assert that when we are uncertain about whether an animal feels pain, we should entertain the 
possibility that she does and that this consideration should enter into how we treat her. Thus, if we are not very sure that an individual will not suffer when exposed to a given situation, we should not expose that individual to the given situation until we are very sure that she will not suffer.

I would also like to add that it is important that we make serious attempts to take the animal's point of view (see Bekoff, 1991; Bekoff, Gruen, Townsend, \& Rollin, 1992; Dawkins, 1990), and try to discover answers to the fascinating question of how individual animals interact in their own worlds and why they do so-what it would be like to be a particular individual from his or her own perspective, not merely from our tainted view or from typological thinking about members of the same or closely related species. Limited time, expense, and methodological difficulties should not be used as excuses for producing hasty and misleading views on the ways in which an animal interacts in her world-positions that might bear strongly on how she is treated. Other individuals may not be like us because they are not one of us, and they may be different from other members of the same or closely related species because of genetic or acquired variation. Although some animals seem to respond in the same way that some humans do to a wide variety of stimuli that are known to us to be pleasurable or painful, we also know that many other animals process sensory information differently from most humans and that many animals also perform motor activities that are unlike those that most humans typically perform.

SK: I suppose that you also want to argue that some animals may also have beliefs and desires and maybe even communicate using language and behave intentionally? After all, if we cannot prove that they do not, they just may.

PRO: Yes, you are right once again! ${ }^{4}$ I claim that we must not assume that individual animals do not have their own sets of beliefs and desires, even if they do not possess what we call "language" or have concepts similar to the ones that we use to explain their behavior. A little common sense is needed in our explanations of why animals do the things that they do. And just because some animals may suffer and feel pain and manifest pain and suffering behaviorally or physiologically in ways that are different from how most humans do, we must not conclude that these animals do not suffer because they do not behave like most humans do when they suffer.

SK: No, the burden of proof does not lie on us. When we do not know something we should not grant any special consideration. Also, common-sense explanations can be wrong.

PRO: But, of course, common-sense explanations can also be right. Furthermore, we cannot conclude that another animal, human or nonhuman, cannot do something when she does not do what we expect her to do, until we are sure that we have provided her with the environment, social and otherwise, that favors the performance of a given behavior pattern. If we use the criterion that the animal must be able to perform some sort of behavior from which we can infer some type of mentation or infer that the animal feels pain, then we must be certain that the animal can perceive the necessary stimuli, is able to perform the motor activity that we think he should perform, and is motivated to perform this task. Furthermore, when an individual animal makes what we call an "error," it may not be an error in the context in which it was made-when that individual's sensory (and perhaps motor) world is taken into account. 


\section{SUMMARY}

We are proponents. We argue for the need to shift focus from species or group membership to individual characteristics. For decision-making purposes, this shift is crucial as a way of avoiding prejudicial judgments. We do not mean to suggest that the concepts of species or group membership are never useful or important. Furthermore, we believe that not only can we know about the pains, sufferings, and minds of other animals but that in many instances we know more than we think. Most animals should be morally considered and treated accordingly until there is strong and reliable evidence that this should not be the case. When in doubt about the capacities for an animal to suffer and feel pain, we should err on the side of that individual and assume that he or she does suffer and feel pain unless there is incontrovertible evidence that this is not the case. Any violation of the moral principles that accompany membership in the moral community must be justified. The burden of proof is always on the human who wants to interfere with individual animals' lives and never on those individuals (Gruen, 1991).

\section{NOTES}

${ }^{1}$ For further discussion on this important issue see Dennett (1978, pp. 267-285) and Wilkes (1988). Wilkes (1988) and Carruthers (1986, pp. 227ft) invoke both rationality and some sort of selfconsciousness as being important for the assignment of personhood. Wilkes (1988) noted that "we know of no non-humans such that any significant number of people regard them as true persons" (p. 22), and also that "all persons so far are human beings" (p. 230). However, she also noted that it really is very difficult to make claims about animals into whose worlds we have limited access. Carruthers concluded that although there are some human beings who are not persons, I am myself doubtful whether any nonhuman animals are in fact persons to any degree; though I have made no attempt to survey the details of the evidence [italics added]" (p. 240). Clearly, the notion of personhood is a difficult one (even historically; see, e.g., Noonan, 1991), and it is still too early to make any sweeping statements as to which animals may justifiably be called persons and which humans may be excluded from being called persons. If having a sense of justice is also a possible criterion for the assignment of personhood, then even this characteristic does not clear up matters because it remains possible that at least a chimpanzee's sense of social regularity may be related to a human's sense of justice (deWaal, 1991).

${ }^{2}$ For discussion see Bekoff (1976), Bekoff and Jamieson (1991), and Rollin (1989). People may also disagree on just what causes harm. For example, in a children's book on cowboys, Fletcher (1959) noted that with respect to branding, "the branding iron, heated until 'cherry red,' is held against the calf's flank for a half a minute. It scorches the hair and leaves a scar but doesn't really hurt the calf." It should be noted that many cowboys do indeed disagree with this statement (B. Rollin, personal communication, September, 1989).

${ }^{3}$ See also Bradshaw (1990) and Bekoff (1991). Common sense often informs arguments about the subjective states of animals. We maintain that in many instances we really do know more about animal pain and suffering than we often claim; the hesitancy that many of us state concerning the pain and suffering of animals is grounded in our fear of being labeled "too anthropomorphic." As Smith and Boyd (1991) concluded, after an extensive review of evidence for and against the possibility of animals experiencing pain, stress, and anxiety, if it is rational for one to generalize "from their own feelings to other humans beings ... it is no less rational to extend the generalization to other species" (p. 73). It is highly likely that others who act nothing like we do when we feel pain really do feel pain (Lewis, 1980). 
${ }^{4}$ For discussions of research in cognitive ethology, in which evolutionary and comparative analyses are made of animal thought processes, consciousness, beliefs, and rationality, see Bekoff and Jamieson (1991), Bekoff (1994, in press), Bekoff and Allen (1994), and Jamieson and Bekoff (in press).

\section{ACKNOWLEDGMENTS}

We thank Kenneth J. Shapiro, Peter Singer, Randolf DiDomenico, Susan Townsend, Carol Powley, Dale Jamieson, Bernard Rollin, and Deborah Crowell for remarks on this article. They do not necessarily agree with our conclusions.

\section{REFERENCES}

Bedau, H. A. (1991). Ethical aspects of environmental decision making. In R. A. Chechile \& S. Carlisle (Eds.), Environmental decision making: A multidisciplinary perspective (pp. 176-194). New York: Van Nostrand Reinhold.

Bekoff, M. (1976). The ethics of experimenting with nonhuman animals: Should man judge by vision alone? The Biologist, 58, 30-31.

Bekoff, M. (1991). The animal's point of view, animal welfare, and some other related matters. Behavioral and Brain Sciences, 14, 753-755.

Bekoff, M. (1992). What is a "scale of life"? Environmental Values, 1, 253-256.

Bekoff, M. (1994). Cognitive ethology and the explanation of nonhuman animal behavior. In J.-A. Meyer \& H. L. Roitblat (Eds.), Comparative approaches to cognitive science. Cambridge, MA: MIT Press.

Bekoff, M. (in press). Review of Donald R. Griffin's Animal minds: Ethology.

Bekoff, M., \& Allen, C. (1994). Cognitive ethology: Slayers, skeptics, and proponents. In R. W. Mitchell, N. Thompson, \& L. Miles (Eds.), Anthropomorphism, anecdotes, and animals: The emperor's new clothes? Lincoln: University of Nebraska Press.

Bekoff, M., Gruen, L., Townsend, S. E., \& Rollin, B. E. (1992). Animals in science: Some areas revisited. Animal Behaviour, 44, 473-484.

Bekoff, M., \& Jamieson, D. J. (1991). Reflective ethology, applied philosophy, and the moral status of animals. Perspectives in Ethology, 9, 1-47.

Bradshaw, R. H. (1990). The science of animal welfare and the subjective experience of animals. Applied Animal Behaviour Science, 26, 191-193.

Carruthers, P. (1986). Introducing persons: Theories and arguments in the philosophy of mind. Albany: State University of New York Press.

Croft, D. B. (Ed.). (1991). Australian people and animals in today's dreamtime. New York: Praeger.

Dawkins, M.S. (1990). From an animal's point of view: Motivation, fitness, and animal welfare. Behavioral and Brain Sciences, 13, 1-61.

DeBlieu, J. (1991). Meant to be wild: The struggle to save endangered species. Golden, CO: Fulcrum.

Dennett, D. C. (1978). Conditions of personhood. In D. C. Dennett (Ed.), Brainstorms: Philosophical essays on mind and psychology (pp. 267-285). Cambridge, MA: MIT Press.

deWaal, F. (1991). The chimpanzee's sense of social regularity and its relation to the human sense of justice. American Behavioral Scientist, 34, 335-349.

Fitzgerald, M. (1987). Pain and analgesia in neonates. Trends in Neurosciences, 10, 345-347.

Fletcher, S. E. (1959). The big book of cowboys. New York: Grosset \& Dunlap.

Gaard, G., \& Gruen, L. (in press). Ecofeminism: Toward global justice and planetary health. Society and Nature. 
Geist, V. (1992). Endangered species and the law. Nature, 357, 274-276.

Gibbons, A. (1991). Chimps: More diverse than a barrel of monkeys. Science, 255, 287-288.

Gittleman, J. L., \& Pimm, S. L. (1991). Crying wolf in North America. Nature, 351, 524-525.

Gruen, L. (1991). Animals. In P. Singer (Ed.), A companion to ethics (pp. 343-353). Oxford, England: Basil Blackwell.

Hursthouse, R. (1987). Beginning lives. Oxford, England: Basil Blackwell.

Jamieson, D. J., \& Bekoff, M. (in press). On aims and methods of cognitive ethology. Philosophy of Science Association.

Johnson, E. (1983). Life, death, and animals. In H. Miller \& W. Williams (Eds.), Ethics and animals (pp. 123-133). Clifton, NJ: Humana.

Kulli, J., \& Koch, C. (1991). Does anesthesia cause loss of consciousness? Trends in Neurosciences, 14, 6-10.

Lewis, D. (1980). Mad pain and martian pain. In N. Block (Ed.), Readings in philosophy of psychology (Vol. I, pp. 216-222). Cambridge, MA: Harvard University Press.

Lott, D. F. (1991). Intraspecific variation in the social systems of wild vertebrates. New York: Cambridge University Press.

McGrew, W. C. (1992). Chimpanazee material culture: Implications for human evolution. New York: Cambridge University Press.

Noonan, H. (1991). Personal identity. New York: Routledge.

Norton, B. J. (1986). The preservation of species: The value of biological diversity. Princeton, NJ: Princeton University Press.

Noske, B. (1989). Humans and other animals: Beyond the boundaries of anthropology. London: Pluto Press.

Pluhar, E. B. (1988). When is it morally acceptable to kill animals? Journal of Agricultural Ethics, 1, 211224.

Rachels, J. (1990). Created from animals: The moral implications of Darwinism. New York: Oxford University Press.

Rollin, B. E. (1989). The unheeded cry: Animal consciousness, animal pain and science. New York: Oxford University Press.

Routley, R., \& Routley, V. (1979). Against the inevitability of human chauvinism. In K. E. Goodpaster \& K. M. Sayre (Eds.), Ethics and problems of the 21st century (pp. 36-59). Notre Dame, IN: University of Notre Dame Press.

Ryder, R. D. (1983). Victims of science: The use of animals in research. London: National Antivivisection Society Ltd. (Original work published 1975)

Ryder, R. D. (1989). Animal revolution: Changing attitudes towards speciesism. Cambridge, MA: Blackwell.

Serpell, J. (1991). Cultural survival, a review of Wenzel, 1991. Animal rights, human rights: Ecology, economy and ideology in the Canadian Arctic: Trends in Ecology and Evolution, 6, 374.

Smith, J. A., \& Boyd, K. M. (1991). Lives in balance: The ethics of using animals in biomedical research. New York: Oxford University Press.

Swartz, K. B., \& Evans, S. (1991). Not all chimpanzees (Pan troglodytes) show self-recognition. Primates, 32, 483-496.

Warren, M. A. (1986). On the moral and legal status of abortion. In M. Pearsall (Ed.), Women and values: Readings in recent feminist philosophy (pp. 279-291). Belmont, CA: Wadsworth.

Wenzel, G. (1991). Animal rights, human rights: Ecology, economy and ideology in the Canadian Arctic. Toronto: University of Toronto Press.

Wilkes, K. V. (1988). Real people: Personal identity without thought experiments. New York: Oxford University Press. 